\title{
Slotartikel: Het oplossend vermogen van living labs
}

\author{
Ellen van Bueren, Philip Marcel Karré \& Iris Vanhommerig
}

In dit slotartikel vatten wij de opbrengsten samen van de individuele artikelen uit dit themanummer en trekken wij een aantal overkoepelende lessen. Wij komen tot de conclusie dat in het kader van de stad als living lab meer aandacht geschonken moet worden aan drie uitdagingen: (1) onduidelijke of tegenstrijdige doelen en verwachtingen, (2) organisatorische onduidelijkheid en (3) de ontbrekende institutionele inbedding en verankering. Op basis hiervan doen we een aantal aanbevelingen voor bestuurskundig onderzoek en de praktijk.

\section{Inleiding: opbrengsten thema-artikelen}

In dit themanummer hebben we stilgestaan bij wat er vandaag de dag allemaal wordt verwacht van steden en hun bestuurders, met name het idee van steden als living labs, laboratoria voor sociale vernieuwing. Wij hebben een aantal vragen gekoppeld aan deze ontwikkeling: wat zijn living labs nu eigenlijk, wat kunnen we ervan verwachten en wat zijn de ervaringen? In het inleidende artikel laten we zien dat de term living lab nogal diffuus is, maar voornamelijk wordt gebruikt voor allerhande lokale initiatieven waarin diverse individuen, groepen en organisaties gezamenlijk tot oplossingen moeten komen die de betrokkenen passen. Gedreven door enthousiasme, daadkracht en geholpen door de tijdgeest heeft bijna elke gemeente nu wel een of meer living labs. Het lijkt er zelfs op dat steden in het algemeen inmiddels worden gezien als grootschalige sociale laboratoria, waar op innovatieve manieren oplossingen worden geproduceerd voor allerlei vraagstukken waar de hedendaagse maatschappij zich mee geconfronteerd ziet, van keuzes over speeltuintoestellen tot de preventie van terrorisme. De veelvuldige verwijzingen naar Barber en geestverwanten bevestigen het grote vertrouwen in lokale daadkracht, met burgemeesters als grote roergangers en als de vereenzelviging van apolitiek bestuur. Samen met betrokken burgers, waaronder een steeds groter wordende groep van op maatschappelijke innovatie gerichte zzp'ers, lijken zij de aanvoerders van een heuse bestuurlijke en maatschappelijke grassroots-revolutie, die ontspringt op lokaal niveau (De Boer \& Van der Lans, 2014; Rotmans, 2015).

Tegelijkertijd constateerden we ook dat de verwachtingen van living labs hoog- en misschien zelfs een tikje overspannen zijn. De beweringen die de pleitbezorgers van deze ontwikkeling maken, en de aannames waar zij hun visie op baseren, klinken uitermate plausibel; empirisch onderzoek dat deze staaft, ontbreekt echter in veel gevallen nog (Mensink, Birrer, \& Dutilleul, 2010; Hellstrom-Reimer, McCormick, Nilsson, \& Arsenault, 2012; Lub, 2013; Uitermark, 2014). Dat betekent, dat 
terwijl deze ontwikkeling doordendert, een aantal belangrijke vragen nog steeds wacht op een antwoord, zoals: In hoeverre zijn living labs inderdaad de power houses voor de productie van oplossingen voor en door burgers? Kunnen steden alle verwachtingen wel waarmaken en is de ontwikkeling die achter het idee van de living labs schuilgaan, alleen maar toe te juichen? Op basis van de artikelen in dit themanummer alsook wat andere wetenschappers reeds hebben gepubliceerd over deze onderwerpen en vragen, constateren we dat er op drie terreinen nog heel wat werk te verrichten valt om living labs tot een succes te maken. Wij kijken (1) naar de soms nog onduidelijke doelen en verwachtingen rondom living labs, (2) hun organisatorische strubbelingen en (3) de soms nog ontbrekende institutionele inbedding en verankering.

Voorafgaand aan deze beschouwing moet wel worden opgemerkt, dat dit geen pleidooi is tegen dit soort lokale initiatieven en dat we bewondering hebben voor al de groepen burgers die problemen in hun leefomgeving zelfstandig of in samenwerking met andere partijen willen aanpakken. Dit is dus geen cynisch, onnodig kritisch verhaal - een verwijt dat je snel kunt krijgen bij een wat meer genuanceerd betoog over deze ontwikkelingen (zie bijvoorbeeld het debat tussen Jan Rotmans enerzijds en Evelyn Tonkens en Jan-Willem Duyvendak anderzijds in januari 2015 op de website socialevraagstukken.nl). Maar tegelijkertijd vinden wij het, op basis van wat we zien gebeuren, ook lastig om al te snel mee te gaan in het vaak te beluisterende betoog waarin living labs en andere nieuwe vormen van samenwerking en de aanpak van maatschappelijke vraagstukken bijna als een nieuwe soort heilsleer lijken te worden gepresenteerd. Deze indruk ontstaat door veel beschrijvingen van wat er in veel wijken en buurten, bijvoorbeeld in de vorm van living labs, op dit moment gebeurt en wat in het algemeen hun potentie is. Deze betogen zijn vaak min of meer anekdotisch van aard en/of hebben een erg activistische ondertoon. Misschien hoort dit wel bij een ontwikkeling die velen als een revolutie beschouwen; die, eerlijk is eerlijk, een overheid die zich tot grootschalige bezuinigingen gedwongen ziet, ook goed uitkomt; en die een groep nieuwe professionals en zzp'ers de kans geeft een inkomen bij elkaar te sprokkelen. Hier zit een zeker afbreukrisico in verscholen. Cynisme en teleurstelling zullen juist ontstaan, als het in de praktijk toch lastiger lijkt dan gedacht om tot een werkende innovatieve aanpak te komen, die maatschappelijke problemen duurzaam het hoofd biedt. Mede daarom is het volgens ons belangrijk de volgende drie conclusies mee te nemen in de opzet, facilitatie en het management van situationele, participatieve samenwerkingsverbanden tussen overheden, burgers en bedrijven à la living labs.

\section{Drie overkoepelende conclusies}

\section{Conclusie I: Onduidelijke of tegenstrijdige doelen en verwachtingen vragen om procesaanpak}

Het artikel van De Jong et al. in dit nummer laat zien dat ambities van stadsbesturen wereldwijd vaak in grote concepten worden weergegeven. Met wer- 
vende, alomvattende concepten probeert een stadsbestuur richting te geven aan het handelen van actoren. Deze concepten inspireren stadsbestuurders, burgers en allerlei andere groepen van actoren in de stad tot actie. Ook in Nederland spelen ze ongetwijfeld een rol in het tot stand komen van de vele initiatieven waarin groepen bewoners, woningcorporaties, energiemaatschappijen en andere actoren werken aan verbetering van straat, buurt of stad. Denk bijvoorbeeld aan de ambities van Rotterdam, aangesloten bij het initiatief van Bill Clintons stichting om de CO2-uitstoot met $50 \%$ te verminderen. In de praktijk blijken deze concepten echter ambigu en vol tegenstrijdigheden. Het is de vraag of dit soort wenkende concepten voldoende houvast bieden om te worden uitgewerkt in praktischer concepten die kunnen worden beproefd in testomgevingen.

Daar waar living labs in commerciële bedrijven in de productinnovatie worden ingezet ter validering en eventueel mede-ontwikkeling van technologie door gebruikers, blijken veel stedelijke living labs opgezet om slecht afgebakende problemen in een bepaald gebied op te pakken. Deze gebiedsgerichte insteek is een logische vanuit de optiek van de wens tot kleinschaligheid, dicht bij de burger, en de behoefte om buurt- en wijkgebaseerde netwerken te creëren of te verstevigen, die burgers helpen de zorg voor elkaar en voor de directe omgeving op te pakken. Maar zonder verdere focus leent de gebiedsgerichte insteek zich slecht voor daadwerkelijke innovatie. Veel van de vraagstukken waar in het kader van living labs aan wordt gewerkt, hebben immers het karakter van hardnekkige (wicked) beleidsproblemen. Er is dus niet alleen geen overeenstemming over wat het probleem precies is, maar ook niet over hoe dat zou kunnen worden aangepakt. In dit rationele vacuüm zijn het juist de waarden, belangen en normatieve voorkeuren van betrokkenen, die een belangrijke rol spelen (zie bijvoorbeeld ook Bestuurskunde, 23(2)). Dat vereist een vorm van samenwerking die hiermee rekening houdt, een vorm van procesmanagement in plaats van een meer projectmatige aanpak die past bij de meer traditionele invulling van living lab als omgeving voor het doelgericht ontwikkelen en testen van een innovatie (zie o.a. De Bruijn \& Ten Heuvelhof, 2007). Het ontwikkelen en testen van innovatie vereist een zekere afbakening en sturing die zich moeizaam verhoudt met de bottom-up initiatieven waarin burgers zelf tot innovatie willen komen.

De praktijkreflecties van Nijboer en Van Winden laten zien, dat dit ook in de Nederlandse praktijk een groot probleem vormt. Zo schetst Nijboer het risico te beginnen met samenwerking binnen een living lab, zonder uitgebreide discussie over onderlinge waarden en de verwachtingen en doelen van de betrokken partijen. Samenwerking zonder inhoud, die een doel op zich is geworden, zal uiteindelijk alleen maar frustratie opleveren. Van Winden heeft het over de fricties die ontstaan door tegenstrijdige waarden en belangen. Dat het ontbreken van een gezamenlijk doel niet bevorderlijk is voor samenwerking, is op zich geen nieuwe of verrassende constatering, maar geeft wel het belang aan van het aan de voorkant inzichtelijk maken van de onderlinge verschillen. Zo te zien hebben living labs te maken met dezelfde uitdagingen als alle grote, multidisciplinaire samen- 
werkingsverbanden rondom complexe en ambigue maatschappelijke problematiek.

\section{Conclusie II: Organisatorische onduidelijkheid}

In de stedelijke omgeving komt het nieuwe speelveld van de participatiemaatschappij of de energieke samenleving bij uitstek naar voren. Rondom praktische problemen en taken tasten overheden, burgers en bedrijven de veranderde verhoudingen af en zoeken zij naar nieuwe vormen van samenwerken. De living labs vormen een omgeving waarin nieuwe rollen kunnen worden uitgeprobeerd. Vanuit hun praktijkervaring met living labs beschrijven Van Winden en Nijboer dat de betreffende gemeenten het nog lastig vinden niet terug te vallen in hun oude rol als opdrachtgever of regelgever. Burgers en bedrijven wacht een vergelijkbare valkuil. Ook zij zijn geneigd te vervallen in oude rolpatronen, bijvoorbeeld door het weigeren van medewerking of het vragen om subsidie. Maar het vasthouden aan oude verhoudingen frustreert samenwerking. Het is interessant om na te gaan hoe deze rollen en de mechanismen die erachter schuilgaan te veranderen zijn. Je kunt als ambtenaar wel graag samen willen werken, maar welke kans maak je met een wethouder die 'zijn' geld vooral wil gebruiken om zelf aan het roer te staan en te kunnen scoren? En welke kans maak je als 'faciliterend' ambtenaar met mondige en vooral zeer kritische burgers die zelf ook duidelijke ideeën hebben bij hoe publiek geld besteed moet worden, zeker als zij daar zelf geen begunstigden van zijn? Voor overheden is het niet eenvoudig om in te schatten hoe zij op een constructieve wijze als overheid kunnen bijdragen aan deze initiatieven.

Het lastige, of, positief geformuleerd, het uitdagende aan doelzoekende living labs is voorts dat de spelers niet of slechts beperkt vooraf gedefinieerd zijn. De problemen die in deze labs of initiatieven worden geadresseerd, vragen om nieuwe of andere oplossingen, spelregels en spelers. Met name de spontaan ontstane initiatieven trekken een varia aan van betrokken, maar (nog) relatief ongeorganiseerde groepen van burgers, maatschappelijke organisaties en nieuwe spelers. Daarnaast zijn er vaak 'incumbents' aanwezig, grote spelers die hun marktaandeel zien afbrokkelen en op zoek zijn naar nieuwe mogelijkheden. Aangezien living labs ook voortkomen uit de behoefte tot nieuwe oplossingen, is het niet zonder meer aannemelijk dat deze 'incumbents' tot gewenste innovaties kunnen komen, nog even afgezien van de gevestigde belangen die zij toch ook moeten behartigen.

Dan is er ook nog de vraag of alle benodigde actoren betrokken zijn: is de benodigde productiemacht aanwezig? In zijn Van Slingelandt-lezing wees Henk de Jong hiernaar: ook de invloed van ogenschijnlijk machtige burgemeesters, zoals die van New York, is sterk afhankelijk van de medewerking van organisaties die actief zijn op andere niveaus of in andere jurisdicties. Zo is het voor de gemeente Rotterdam ondoenlijk om de 50\% CO2-reductiedoelstelling te behalen zonder betrokkenheid van de petrochemische industrie in de haven. Het is de vraag in hoeverre deze wereldspelers, die zich vooral laten leiden door macro-economische 
en geopolitieke factoren, een rol willen of kunnen spelen in lokale beleidsprocessen.

Iets vergelijkbaars geldt voor de smart city doelstellingen van gemeenten als Amsterdam: het gebruik kunnen maken van urban big data, ook in kleinschalige, lokale projecten, vereist technologie en kennis van grote, globale spelers als technologiebedrijven Siemens, Cisco en IBM, adviseurs als Accenture en de toegang tot data van netwerkbeheerders als Liander en energieleveranciers als Vattenfall. Hoe welwillend alle betrokkenen ook tegenover de samenwerking staan, het is duidelijk dat er grote verschillen zijn tussen betrokken actoren in living labs op het gebied van kennis, capaciteit en belangen. Het overbruggen van deze verschillen is in living labs, net als in elk samenwerkingsproject, een flinke uitdaging. Juist daarin zouden gemeenten een rol kunnen spelen. Maar dat faciliteren is niet altijd eenvoudig. Niet alleen omdat de gemeentelijke organisatie daarop nog niet is ingespeeld, maar ook omdat de gemeente soms in verschillende rollen aanwezig is, en tevens belanghebbende kan zijn. Het innemen van een apolitieke, faciliterende rol is dan niet zonder meer vanzelfsprekend en kan op gespannen voet staan met het benodigde vertrouwen van betrokkenen in die ondersteuning. Overigens laten ervaringen met procesmanagement in stedelijke ontwikkelingsprocessen zien dat dit best kan, mits de procesmanager en de gemeente hierover transparant zijn.

\section{Conclusie III: Behoefte aan institutionele inbedding en verankering}

Het artikel van Van der Steen en De Jong en de lezing van Henk de Jong benadrukken dat steden onderdeel uitmaken van verschillende netwerken. Zo ook maken bewoners, burgers onderdeel uit van verschillende netwerken. En juist die netwerken van bewoners zijn minder geografisch georganiseerd dan gemeenten met hun stadsdelen, wijken en buurten. Meijs, Ter Meer en Burgers (2014) wijzen er dan ook op dat er een verschuiving nodig is in het denken van gemeenten naar gemeenschappen. Zij zien voor de gemeentelijke overheid vooral een rol weggelegd in de ondersteuning van deze gemeenschappen. Daar waar de gemeenschappen passen bij beleidsdoelstellingen kan de gemeente actiever aansluiting zoeken bij de initiatieven, daar waar het niet past kan de gemeente desondanks een faciliterende bijdrage leveren. Vertrouwen speelt in alle gevallen een grote rol; gemeenten en gemeenschappen moeten elkaar kennen en erkennen.

Het elkaar leren kennen en erkennen speelt ook een grote rol in de Kennis voor Krachtige Steden-aanpak zoals beschreven door Duiveman in dit nummer. Het gezamenlijk verkennen van problemen doet recht aan de ongestructureerdheid ervan. Tegelijkertijd doet het een beroep op ieders oplossingsvermogen, en kunnen interessante combinaties en cross-overs ontstaan tussen praktijk en wetenschap en tussen sectoren en disciplines.

Het gezamenlijk leren, en de mogelijke ondersteuning daarvan door gemeenten, kan worden ingebed in procedures en praktijken. Maar dergelijke institutionalisering kost tijd en het veronderstelt een meta-leervermogen: het vermogen om te leren leren. Dit komt bijvoorbeeld tot uitdrukking in de learning labs tussen ken- 
nisinstellingen en overheden, zoals Van Winden die ook beschrijft in zijn praktijkreflectie. Om deze labs goed tot hun recht te laten komen is een meer structurele inbedding nodig, bijvoorbeeld aan de hand van een programma dat voor langere termijn een kader biedt waarbinnen leeropdrachten kunnen worden geformuleerd en dat beleidsmakers een referentiekader biedt om te leren van de diverse ervaringen. Tevens verkleint dit de transactiekosten om elkaar telkens opnieuw te kunnen vinden.

Een ander aspect van de schaalvraag is die van de schaalbaarheid van problemen. De living labs en maatschappelijke initiatieven zijn vaak van beperkte schaal. Vanuit een sturende rol bekijken overheden deze initiatieven vaak met een schaalbaarheidsbril: hoe kunnen we de praktijk die is ontwikkeld in het living lab op grotere schaal toepassen, uitrollen over andere wijken en steden? Het is de vraag in hoeverre dit een-op-een kan. Juist omdat gemeenschappen in living labs en andere maatschappelijke initiatieven een grote rol spelen, zijn dit intensieve, evoluerende en context-gebonden processen met hun eigen dynamiek. De tijd en inspanning die met deze processen gemoeid gaan, staan op gespannen voet met veronderstelde schaalvoordelen. Uiteraard kunnen lessen en ervaringen en innovaties uit het ene lab worden toegepast in andere labs, maar het is de vraag of dat heel veel winst in de term van schaalvoordelen oplevert. Zo zijn succesvolle energierenovatieprojecten van woningen het resultaat van een betrokken netwerk van lokale partijen, zoals lokale aannemers en installateurs, en is een centrale rol weggelegd voor energieambassadeurs, bewoners uit de wijk zelf. Tegelijkertijd kunnen ervaringen uit living labs wel degelijk van invloed zijn op andere schaalniveaus, bijvoorbeeld door aanpassing van wet- en regelgeving. Het evidence-based karakter van opgedane ervaringen in living labs levert overtuigende verhalen op die duidelijk kunnen laten zien welke institutionele belemmeringen er zijn, en soms zelfs beproefde oplossingen presenteren.

Tot slot is daar de relatie met andere schalen. Hoe kunnen de living labs en de daar opgedane ervaringen worden gekoppeld aan probleemdimensies die zich op andere schaalniveaus bevinden? Hoe wordt voorkomen dat living labs, vanwege hun beperkte schaal, oplossingen die zich buiten de schaal bevinden over het hoofd zien? Het beeld van de stad als knooppunt van netwerken op verschillende niveaus leent zich hier goed voor, zoals geschetst in het artikel van Van der Steen en De Jong. Vanwege de beperkte invloedssfeer van gemeenten is het goed om te kunnen opereren in netwerken, waarbij verbindingen dienen te worden gezocht door de schalen heen. Netwerkers, verbinders, entrepreneurs zijn onmisbaar voor het goed kunnen schakelen tussen deze processen en het leggen van de verbindingen. Tegelijkertijd kan dit op gespannen voet staan met de verantwoordingsstructuur. Het kunnen manoeuvreren tussen nieuwe rollen en taken en met institutionele kaders die daar nog niet op toegesneden zijn en wellicht resulteren in resultaten die niet zonder meer voor alle burgers een zelfde resultaat opleveren, is niet altijd makkelijk in een tijd waarin bestuurlijke integriteit onder het vergrootglas ligt. 


\section{Aanbevelingen voor onderzoek en praktijk}

In het politiek-maatschappelijk discours wordt veel gesproken en geschreven over living labs en de positieve bijdragen die zij zouden kunnen leveren aan de aanpak van maatschappelijke vraagstukken. Daarbij, zo laten de artikelen uit dit themanummer zien, hebben living labs echter te maken met een aantal uitdagingen. Of living labs en andere nieuwe manieren om maatschappelijke vraagstukken aan te pakken, waarin de burger het voortouw neemt, daadwerkelijk zullen leiden tot een revolutie (of daar misschien een voorbeeld voor zijn), laat zich op basis van de artikelen in dit themanummer nog niet beantwoorden.

De beoordeling van de participatiemaatschappij als sturingsparadigma is een lastige. Zo concluderen Voorberg, Tummers en Bekkers (2015) op basis van een uitgebreide literatuurstudie, dat we niet echt weten wat coproductie tussen verschillende partijen in het kader van de participatiesamenleving nu echt oplevert. Ook al wordt dit vaak beweerd en lijkt het aannemelijk en plausibel om ervan uit te gaan - wij weten eenvoudig gewoon nog niet of co-creatie en coproductie inderdaad voor minder kosten, meer legitimiteit en meer vertrouwen zorgen tussen burgers en overheid. Vooralsnog is de participatiemaatschappij alom aanwezig en moet er in de praktijk nog verder invulling aan worden geven. Veel is nog onbekend ten aanzien van wat werkt en wat niet werkt.

De bestuurskunde kan een belangrijke rol spelen bij het vullen van deze kennislacunes, alsook bij het aanreiken van concrete aanbevelingen, bijvoorbeeld ten aanzien van de drie uitdagingen die wij op basis van dit themanummer signaleren. Doel is dan wat ons betreft om aan het politiek-maatschappelijk discours over wat steden kunnen bereiken in de aanpak van maatschappelijke vraagstukken (een discours dat bol staat van de grote verwachtingen) een nuchter wetenschappelijk-analytisch perspectief toe te voegen. Wat weten we al over wat wel of niet gaat werken en waar is meer aandacht voor nodig? En welke handelingsopties hebben de betrokken partijen dit allemaal in overweging nemende? Als een van nature interdisciplinaire, praktijk- én handelingsgerichte wetenschap kan de bestuurskunde, zeker na ruim dertig jaar onderzoek over en ervaringen met werken in governance-achtige settings, aangeven waar op dit moment blinde vlekken te constateren zijn in de ontwikkelingen rondom living labs en hoe die te verhelpen zijn. Ervaringen en lessen uit het verleden kunnen helpen te voorkomen, dat opnieuw dezelfde fouten worden gemaakt. Beleid dat alleen stoelt op plausibel klinkende aannames, heeft immers grote kans om te mislukken en ten onder te gaan aan beleidsamnesie (zie bijvoorbeeld Lub, 2013).

\section{Literatuur}

Boer, N. de, \& Lans, J. van der. (2014). DEcentraal: De stad als sociaal laboratorium. Amsterdam: Atlas Contact.

Bruijn, H. de, \& Heuvelhof, E. ten. (2007). Management in netwerken: Over veranderen in een multi-actorcontext. Den Haag: Uitgeverij Lemma. 
Hellstrom-Reimer, M., McCormick, K., Nilsson, E., \& Arsenault, N. (2012). Advancing sustainable urban transformation through living labs. In International Conference on Sustainability Transitions, 29-31.

Meijs, L., Meer, J. ter, \& Burgers, L. (2014). Oplossingen lokale problemen liggen niet bij colleges maar bij burgers. Sociale Vraagstukken.http://www.socialevraagstukken.nl/ site/2014/04/15/de-juiste-coalities-zijn-al-gevormd.

Mensink, W., Birrer, F.A., \& Dutilleul, B. (2010). Unpacking European living labs: Analysing innovation's social dimensions. Central European Journal of Public Policy, (1), 60-85.

Lub, V. (2013). Schoon, heel en werkzaam? Sociale interventies op het terrein van leefbaarheid wetenschappelijk beoordeeld. Den Haag: Boom Lemma uitgevers.

Rotmans, J. (2015). Verandering van tijdperk: Nederland kantelt. Boxtel: Aeneas.

Uitermark, J. (2014). Verlangen naar Wikitopia. Rotterdam: Erasmus Universiteit Rotterdam.

Voorberg, W., Tummers, L., \& Bekkers, V. (2015). De participatiesamenleving, we weten niet wat het oplevert. Sociale Vraagstukken.http://www.socialevraagstukken.nl/site/ 2015/01/23/de-participatiesamenleving-we-weten-niet-wat-het-oplevert/. 